\title{
Decay Correction Indicator
}

National Cancer Institute

\section{Source}

National Cancer Institute. Decay Correction Indicator. NCI Thesaurus. Code C116127.

An indication as to whether the image reconstruction took into account the time-activity curve during which the radiolabeled tracer decayed as it spread through the body during the image acquisition. 